\title{
Daily Associations Between Drinking and Sex Among College Students: A Longitudinal Measurement Burst Design
}

\author{
Megan E. Patrick \\ University of Michigan
}

\author{
Jennifer L. Maggs and Eva S. Lefkowitz \\ Pennsylvania State University
}

\begin{abstract}
Daily links between alcohol use and sexual behaviors were examined in a longitudinal study of college students. Hierarchical linear models predicted sexual behaviors by characteristics of persons $(N=731$, Level 3$)$, semesters $(N=4,345$, Level 2), and days ( $N=56,372$, Level 1). On a given day, consuming more drinks and binge drinking were associated with greater odds of kissing, touching, oral sex, and penetrative sex. Consistent with alcohol myopia and expectancy theories, associations between binge drinking and sexual behaviors were stronger for students not in romantic relationships, for students with stronger alcohol-sex expectancies, and for oral and penetrative sex. Findings suggest that within-day links between alcohol use and sexual behaviors are evident across college, with variations based on individual and relationship factors.
\end{abstract}

Experimentation with alcohol use (Brown et al., 2008; Johnston, O’Malley, Bachman, \& Schulenberg, 2013a) and the emergence of sexual interest and sexual behaviors (Lefkowitz \& Gillen, 2005; Tolman \& McClelland, 2011) are normative features of adolescent and young adult development. Alcohol use and sexual behaviors can co-occur; for example, engaging in sexual behaviors after drinking is frequently described as a consequence of college student alcohol use (Hingson, Heeren, Winter, \& Wechsler, 2005; Hingson, Heeren, Zakocs, Kopstein, \& Wechsler, 2002; Perkins, 2002). The majority of evidence documenting associations between alcohol use and sex is based on cross-sectional studies, which suggest that people who drink more heavily also tend to engage in more sexual behaviors. However, cross-sectional studies cannot address whether alcohol use is in fact associated with an increased likelihood of sexual behaviors on the same day for a given individual (Cooper, 2006) or how links may change developmentally across young adulthood with increased maturity and relationship experience. The college years tend to correspond to high rates of exploration for both alcohol use and sexual behaviors; the prevalence of both behaviors and the potential risks involved make college students a relevant population for the

This research was supported by Grant R01 AA016016 to J. Maggs from the National Institute on Alcohol Abuse and Alcoholism. The content here is solely the responsibility of the authors and does not necessarily represent the official views of the sponsor.

Requests for reprints should be sent to Megan E. Patrick, Institute for Social Research, University of Michigan, Ann Arbor, MI 48106-1248. E-mail: meganpat@umich.edu study described here. This study examines the fundamental questions of whether sexual behaviors are more likely on days college students consume alcohol, whether relationship status and alcoholsex expectancies moderate this association, and whether day-to-day links between alcohol use and sex change developmentally across the college years. Advancing prior work, we also consider a wider range of developmentally normative sexual behaviors, including kissing, touching, oral sex, and penetrative sex.

\section{Linking Alcohol and Sexual Behaviors}

Two primary models identify mechanisms that may explain why alcohol use is linked with sexual behaviors. First, alcohol myopia theory proposes that intoxication narrows one's focus to immediate and compelling cues, such as attraction to a potential partner, leading to more willingness to engage in sexual behaviors (Dermen \& Cooper, 2000; Griffin, Umstattd, \& Usdan, 2010; Kaly, Heesacker, \& Frost, 2002; MacDonald, Fong, Zanna, \& Martineau, 2000; Steele \& Josephs, 1990). Second, alcohol expectancy theories posit that expecting alcohol to facilitate sexual behaviors can become a self-fulfilling prophecy, such that people with greater alcohol-sex expectancies will be more likely to have sex after drinking (Coleman \& Cater, 2005; Cooper, 2006; Dermen, Cooper, \& Agocha, 1998; Lang, 1985; Patrick \& Maggs, 2009).

(C) 2014 The Authors

Journal of Research on Adolescence (C) 2014 Society for Research on Adolescence DOI: $10.1111 /$ jora. 12135 
Empirically, hundreds of published studies have examined links between alcohol use and sexual intercourse (Cooper, 2002, 2006). A majority document global between-person associations with the use of cross-sectional or longitudinal designs, demonstrating that people who drink more frequently or intensely also engage in more frequent or varied sexual behaviors. Such between-person links are informative about who has higher odds of ever engaging in sexual behaviors, or of increasing engagement over time, but do not address whether a given individual is more, less, or equally likely to engage in sexual behaviors on occasions when the same person drinks more heavily, compared to days when he or she abstains or drinks less. Moreover, between-person associations cannot identify potential theoretical mechanisms that can in turn inform prevention and intervention approaches.

To address important questions about links between alcohol use and sex, an emerging literature on within-person associations uses repeated measures to compare individuals to themselves across multiple situations. These event- or dailylevel studies aim to test whether, and for whom, drinking on a given day is associated with sexual behaviors that day. Some repeated-measures studies document no within-person association between alcohol use and sexual behaviors (Bailey, Gao, \& Clark, 2006; Gillmore et al., 2002; Leigh, 1993; Leigh, Ames, \& Stacy, 2008); others find that the likelihood of engaging in sexual behaviors or unprotected sex increases on drinking occasions (Barta et al., 2008; Kiene, Barta, Tennen, \& Armeli, 2009; LaBrie, Earleywine, Schiffman, Pedersen, \& Marriot, 2005; Mustanski, 2008; Neal \& Fromme, 2007; Patrick \& Maggs, 2009); and at least one study has found a lower likelihood of sexual behaviors when alcohol is consumed (Leigh, 1993). These conflicting findings underscore the need for additional research. This study examines daily covariation between alcohol use and sexual behaviors and does so across a longer time span than previous studies.

\section{Beyond Penetrative Sex}

An important limitation of prior studies of alcohol use and sexual behaviors is that most have focused on only penetrative sex, sex with casual partners, or sex without condoms or contraception, perhaps due to these behaviors' potential for physical harm and relevance to public and individual health. However, kissing and touching are developmentally normative and emotionally significant sexual behaviors during adolescence and young adulthood (Diamond \& Savin-Williams, 2009; Welsh, Haugen, Widman, Darling, \& Grello, 2005). The links between alcohol use and other sexual behaviors-including kissing, touching, and oral sexare largely unexplored, although the processes described by alcohol myopia and expectancy theories are highly applicable to these behaviors. Understanding the influence of alcohol on a range of sexual behaviors is important for supporting healthy social, emotional, and physical development (Tolman \& McClelland, 2011). Thus, the present findings extend prior work by focusing on both penetrative and nonpenetrative sexual behaviors.

\section{Moderators of Links Between Alcohol and Sexual Behaviors}

We also examine moderators of the associations between alcohol use and sexual behaviors, with a focus on relationship status and alcohol expectancies. Associations between drinking and sex differ as a function of the characteristics of the situation and the people involved (Cooper, 2006). For example, being in an ongoing romantic relationship increases partner availability and mutual willingness to engage in sexual behaviors in varied social and private settings, potentially reducing situationor state-specific links between alcohol use and sexual behaviors. Conversely, among singles or people who are casually dating, alcohol myopia theory suggests that the co-presence of alcohol and new potential partners in social milieus such as bars or parties may increase links between drinking and sexual behaviors. Indeed, alcohol tends to be a stronger predictor of sex and unprotected sex with casual partners than with steady partners (Brown \& Vanable, 2007; Cooper, 2002; Kiene et al., 2009).

Additional characteristics of the person, including expectancies about whether and how alcohol might impact sexual behaviors, may also be important. In line with alcohol expectancy theory (e.g., Cooper, 2006), individuals with more positive alcohol-sex expectancies - that is, those who believe alcohol has facilitative effects on sexual confidence, feelings, desire, or performance-may be more likely to engage in sexual behaviors after drinking (Patrick \& Maggs, 2009; Pedersen, Lee, Larimer, \& Neighbors, 2009; White, Fleming, Catalano, \& Bailey, 2009). In this study, we examine relationship status and alcohol expectancies both as main effect predictors and as moderators of the links between alcohol use and sex. 


\section{Developmental Change}

Alcohol use and sexual behaviors are known to be prevalent during the college years, but the links between them and the changing associations across the college years have received less attention. When young adults move away from the parental home, increased behavioral autonomy facilitates widespread exploration of developmentally and socially normative yet potentially risky behaviors, including alcohol use and sexual behaviors (Cooper, 2002; Fromme, Corbin, \& Kruse, 2008). For example, $79 \%$ of U.S. college students have used alcohol in the past year, and 37\% report consuming five or more drinks in a row in the past 2 weeks (compared to $64 \%$ and $24 \%$, respectively, among 12th graders; Johnston et al., 2013a,b). College students experience similar exploration in sexual behaviors; in the past month, $44 \%$ of college students have had oral sex and 49\% have had vaginal sex (American College Health Association, 2007). Longitudinal studies with multiple assessments of alcohol use and sexual behaviors that can identify how both domains change and interrelate developmentally are rare (Dogan, Stockdale, Widaman, \& Conger, 2010). A few available longitudinal analyses (without event-level designs) suggest that associations between drinking and sex may decrease with age across late adolescence to the late 20s (Dogan et al., 2010; Patrick, O'Malley, Johnston, Terry-McElrath, \& Schulenberg, 2012). The present study directly examines how links between alcohol use and sexual behaviors may change during the course of college.

\section{This study}

This study focuses on associations between alcohol use and sexual behaviors and is the first to include repeated daily measurements (assessed in 14-day bursts) across multiple semesters (seven consecutive semesters spanning more than 3 years). This measurement burst design (Nesselroade, 1991; Sliwinski, 2008) disaggregates within-person associations between alcohol use and sexual behaviors at the daily level from associations resulting from developmentally changing semester characteristics (e.g., relationship status, expectancies) and stable between-person differences (e.g., gender, age at the start of college). This design allows us to test the fundamental question of whether sexual behaviors are more likely on drinking days and whether dayto-day links change developmentally across the college years. Whereas the majority of prior work on links between alcohol use and sexual behaviors has been limited to penetrative sex, we also focus on nonpenetrative sexual behaviors, specifically kissing, touching, and oral sex, which have strong developmental significance.

The study has three primary research questions. (1) On days college students consume more drinks or engage in binge drinking, are they more likely to engage in kissing, touching, oral sex, and penetrative sex? (2) Are day-to-day associations between alcohol use and sexual behaviors moderated by relationship status and alcohol-sex expectancies? (3) Do day-to-day links between alcohol use and sexual behaviors change developmentally across the college years?

\section{METHOD}

\section{Participants}

Data from the University Life Study (e.g., Patrick, Maggs, \& Osgood, 2010; Vasilenko, Lefkowitz, \& Maggs, 2012) included 14 consecutive days of daily Web-based surveys during each of seven semesters from fall of first year to fall of fourth year of college ( $\leq 98$ days per participant). A stratified random sampling procedure was used at Semester 1 to achieve a diverse sample of first-year students with respect to gender as well as race and ethnicity. Eligible individuals were first-year, first-time students who were U.S. citizens or permanent residents, younger than 21 years of age through Semester 1, and resided within 25 miles of campus at a large university in the northeastern United States. Students were mailed an informational letter inviting them to participate in the study, followed by an e-mail message with an active hyperlink to the Web-based baseline survey. The day after participants completed the baseline survey, they were invited to begin 14 consecutive short daily Web surveys. Procedures in Semesters 2 through 7 were similar.

In total, 744 students (65.6\% of invited) provided consent and participated in Semester 1 and 608 (81.5\% of Semester 1 sample) participated in Semester 7. Completion rates of the daily surveys were high, with most (79\%-88\%) participants at each semester completing at least 12 of the 14 daily surveys. Data used in these analyses included 56,372 person-days (Level 1), 4,345 person-semesters (Level 2), and 731 persons (Level 3). Thirteen people were dropped from all analyses due to missing data. Based on self-reports to questions about race and Hispanic or Latino ethnicity, the 
sample can be described as 25.1\% Hispanic or Latino American, 27.4\% European American NonHispanic or Latino (NHL), 23.3\% Asian American NHL, $15.7 \%$ African American NHL, and 8.6\% multiracial NHL. At Semester 1, no students were married and $98.1 \%$ identified as heterosexual; at Semester 7, 1.2\% were married and $95.0 \%$ identified as heterosexual.

\section{Measures}

Daily level, measured daily ( $\leq 98$ times per person; 14 days $\times 7$ semesters). Each day, participants reported the number of drinks consumed the prior day, defined as "from the time you woke up until the time you went to sleep." Responses ranged from 0 drinks to $\geq 25$ drinks and were coded as binge drinking (yes $=1, n o=0$ ) if women reported $4+$ drinks and men reported $5+$ drinks (Wechsler \& Nelson, 2001). Each day, participants reported whether they had kissed someone, touched someone underneath their clothing or with no clothing on, engaged in oral sex (receiving or performing), and engaged in penetrative sex (vaginal or anal), each coded as behavior occurred (1) or did not occur (0). Days on which participants reported that alcohol was consumed after the sexual experience were excluded $(0.8 \%$ [2.5\%] of days in Semester 1 [7]), because in those few cases alcohol could not play any clear influential role on sexual behaviors.

Semester level, measured each semester ( $\leq 7$ times per person). Semester mean number of drinks was computed for each person at each semester as the average of drinks consumed across all assessed days in a given semester; the theoretical range was 0 (zero drinks on all days) to 25 ( 25 or more drinks on every reported day). Semester mean binge drinking was the average of daily binge drinking across all days in a given semester, indicating the proportion of assessed days with binge drinking. Relationship status was assessed in each semester with the question, "Which of the following best describes you right now?" Responses were coded as Single ( am not dating anyone right now; reference group), Casual Relationship (I am casually dating someone), or Committed Relationship ( $\mathrm{am}$ in a serious and committed relationship; I am living with my partner; I am engaged; I am married). Alcohol-sex expectancies regarding beliefs about alcohol's effects on sexual drive were assessed each semester (6 items, $\alpha=.95-.96$ across semesters; e.g., "when drinking alcohol, I am likely to initiate sex"; $0=$ not at all to
4 = very much; Abbey, McAuslan, Ross, \& Zawacki, 1999).

Person level (one score per person). Gender was coded as men $=1$ and women $=0$. Age in years at Semester 1 was based on date of birth. Person mean number of drinks at Level 3 was the average number of drinks consumed across all assessed days in all semesters. Person mean binge drinking at Level 3 was the average binge drinking across all days in all semesters.

\section{Plan of Analysis}

Three-level hierarchical linear models (HLM 6.04; Raudenbush \& Bryk, 2002) were used due to the fact that days (Level 1) were nested within semesters (Level 2) that were nested within persons (Level 3). Research Question 1 examined whether sexual behaviors (kissing, touching, oral sex, and penetrative sex) varied as a function of alcohol use (number of drinks, binge drinking) at the daily level (Level 1). Research Question 2 focused on relationship status and alcohol-sex expectancies as moderators of the Level 1 effect of alcohol use on sexual behaviors. Finally, to test Research Question 3 about developmental change in associations, interactions of same-day alcohol use with semester (as a marker of developmental time) were added.

For all research questions, four dichotomous dependent variables-kissing, touching, oral sex, and penetrative sex-were modeled using Bernoulli distributions (with overdispersion). All models included between-person controls at Level 3 (gender, age at Semester 1, and each person's average alcohol use across all reports). Between-semester predictors at Level 2 included a linear effect of semester to test for developmental changes in the likelihood of sexual behaviors; being in a casual relationship and being in a committed relationship that semester (relative to no relationship); alcoholsex expectancies; and average alcohol use across the days that semester. Alcohol use means at the semester (Level 2) and person (Level 3) levels were included as controls to isolate within-person (daily) links. Daily effects at Level 1 included a control variable indicating whether it was a weekend (Thursday, Friday, or Saturday) or weekday (due to large differences between weekend and weekday drinking; Maggs, Williams, \& Lee, 2011); alcohol use that day; and interactions of alcohol use that day with relationship status, expectancies, and semester. 


\section{RESULTS}

\section{Frequency of Alcohol Use and Sexual Behaviors}

Table 1 provides the frequency of engaging in alcohol use and each of the sexual behaviors at each of the three levels (Levels 3 to 1): persons, semesters, and days. At the person level (Level 3), for example, $85 \%$ of people consumed at least one drink and $76 \%$ engaged in kissing on at least one of the up to 98 assessed days. (Note that these figures do not represent the number who ever engaged in these behaviors across the total time interval [more than 3 years], which would undoubtedly be higher, but rather the number who engaged in these behaviors across the sampled days.) Shifting to the person-semester as the unit of analysis (Level 2), during $59 \%$ of semesters people consumed alcohol and during $46 \%$ of semesters people engaged in kissing on at least one of the 14 sampled days. At the daily level (Level 1), 12\% of assessed days included alcohol use and 14\% included kissing. Similar information for binge drinking, touching, oral sex, and penetrative sex is presented in Table 1.

Table 2 shows aggregate descriptive statistics for all predictors and outcome variables, averaged across the relevant intervals. The majority of the variance in sexual behaviors was at Levels 2 and 3 . Intraclass correlation calculations from variance components in unconditional (no predictor) models showed that Level 3 (between-persons) variance was $48 \%$ for kissing, $46 \%$ for touching, $43 \%$ for oral sex, and $46 \%$ for penetrative sex. Level 2 (betweensemesters) variance was $46 \%$ for kissing, $46 \%$ for touching, 52\% for oral sex, and 50\% for penetrative sex. This variance decomposition showed that $4.4 \%$ to $7.8 \%$ of the total variance in the four outcome variables was at Level 1 (within-person) across days.

\section{Controls to Isolate Effects: Person-Level and Semester-Level Predictors}

For all analyses, key Level 3 (person-level) and Level 2 (semester-level) variables were used as controls. Tables 3 and 4 present results for models predicting sexual behaviors from number of drinks and binge drinking, respectively. At Level 3, men had lower odds than women of engaging in each of the four sexual behaviors net of the effects of all other predictors, with the exception of the model in which binge drinking predicted oral sex. Students who were relatively older than their same-cohort peers were less likely to report touch- ing and oral sex. Heavier-drinking students (based on person means) had greater odds of kissing (and marginally greater odds of touching in the binge drinking models only), but not of oral or penetrative sex.

At Level 2, a semester (linear) time trend tested for developmental change in the outcome variables across the college years. Results showed that the odds of oral and penetrative sex increased across semesters, whereas the odds of kissing and touching did not change. During semesters in which students reported being in a casual or committed relationship, they had much greater odds of engaging in all four sexual behaviors. During semesters in which students indicated relatively greater than usual alcohol-sex expectancies and higher drinking (compared to themselves at other times), they were also more likely to engage in all four sexual behaviors.

\section{Daily-Level Alcohol-Sex Associations}

Research Question 1 focused on whether sexual behaviors were more likely on days students consumed more drinks or binge drank, based on Level 1 (daily-level) effects. In all models, consuming more drinks (Table 3) and binge drinking (Table 4) on a given day were associated with greater odds of kissing, touching, oral sex, and penetrative sex that day. The odds of reporting all four sexual behaviors were greater on weekend days (included as a control) compared to weekdays.

\section{Moderation of Alcohol-Sex Associations by Relationship Status and Expectancies}

Research Question 2 focused on whether links between alcohol use and sexual behaviors across days differed as a function of relationship status and alcohol-sex expectancies. In semesters when students were in a casual or committed relationship, the association of number of drinks (Table 3) and binge drinking (Table 4) with all four sexual behaviors was attenuated, relative to semesters students were single. The associations of binge drinking with oral sex and penetrative sex (but not kissing or touching) also showed a trend-level moderation of daily alcohol use by alcohol-sex expectancies. In semesters when students expected drinking to increase sexual drive, the association between binge drinking and oral or penetrative sex was stronger, compared with semesters students reported lower alcohol-sex expectancies. Alcohol-sex expectancies did not 
TABLE 1

Alcohol Use and Sexual Behaviors: Prevalence (in Proportions) Across Persons, Semesters, and Days

\begin{tabular}{lrcccccc}
\hline & $N$ & Any Drinks & Binge Drinking & Kissing & Touching & Oral Sex & Penetrative Sex \\
\hline Persons, Level 3 $^{\mathrm{a}}$ & 731 & 0.85 & 0.70 & 0.76 & 0.68 & 0.56 \\
Person-semesters, Level 2 $^{\mathrm{b}}$ & 4,345 & 0.59 & 0.44 & 0.46 & 0.36 & 0.23 & 0.55 \\
Person-days, Level 1 $^{\mathrm{c}}$ & 56,372 & 0.12 & 0.08 & 0.14 & 0.08 & 0.04 & 0.04 \\
\hline
\end{tabular}

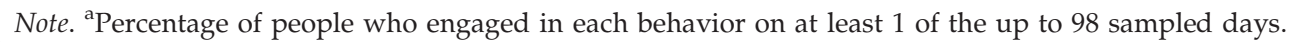

${ }^{b}$ Percentage of all sampled semesters during which people engaged in each behavior on at least 1 of the up to 14 sampled days.

'Percentage of all sampled days on which each behavior was reported.

TABLE 2

Descriptive Statistics

\begin{tabular}{|c|c|c|c|}
\hline & $M$ & $S D$ & Range \\
\hline \multicolumn{4}{|c|}{ Level 3: Person-level constructs, measured once per person } \\
\hline Male gender & 0.49 & 0.50 & $0-1$ \\
\hline Age (at Semester 1) & 18.45 & 0.43 & $16.92-20.75$ \\
\hline Person mean binge drinking & 0.08 & 0.10 & $0-.52$ \\
\hline Person mean number drinks & 0.79 & 1.01 & $0-6.96$ \\
\hline \multicolumn{4}{|c|}{ Level 2: Semester-level constructs, measured each semester } \\
\hline Semester mean binge drinking & 0.09 & 0.13 & $0-1$ \\
\hline Semester mean number drinks & 0.81 & 1.25 & $0-9.33$ \\
\hline Single relationship status & 0.58 & 0.49 & $0-1$ \\
\hline Casual relationship status & 0.11 & 0.32 & $0-1$ \\
\hline Committed relationship status & 0.31 & 0.46 & $0-1$ \\
\hline Alcohol-sex expectancies & 1.32 & 1.14 & $0-4$ \\
\hline \multicolumn{4}{|c|}{ Level 1: Daily-level constructs, measured daily } \\
\hline Binge drinking & 0.08 & 0.27 & $0-1$ \\
\hline Number of drinks & 0.74 & 2.46 & $0-26$ \\
\hline Kissing & 0.14 & 0.35 & $0-1$ \\
\hline Touching & 0.08 & 0.26 & $0-1$ \\
\hline Oral sex & 0.04 & 0.19 & $0-1$ \\
\hline Penetrative sex & 0.04 & 0.21 & $0-1$ \\
\hline
\end{tabular}

Note. $M=$ mean (for dichotomous variables, this number represents the proportion); $S D=$ standard deviation; range = actual range in the data.

Level $3 N=731$ persons, Level $2 N=4,345-4,347$ person-semesters, Level $1 N=55,318-55,372$ person-days.

moderate links between number of drinks and sexual behaviors.

\section{Developmental Change in Alcohol-Sex Associations}

Results for Research Question 3, regarding changes in observed daily-level links between alcohol use and sex across college, showed that the linear time trend of semester (at Level 2) did not moderate the association between drinking and sexual behaviors (at Level 1). That is, the day-to-day association between drinking and sexual behaviors did not change across seven semesters of college.

\section{DISCUSSION}

Alcohol use and sexual behaviors are both developmentally normative behaviors for college students, who typically experiment with behaviors in both domains (Brown et al., 2008; Johnston et al., 2013a; Lefkowitz \& Gillen, 2005; Tolman \& McClelland, 2011). Two important contributions of the current analyses are documenting the presence of day-to-day associations between alcohol use and sexual behaviors among college students and observing that these daily associations did not significantly change across college. Students were more likely to engage in sexual behaviors on days they consumed more alcohol. These findings are consistent with some previous event-level research (Barta et al., 2008; Kiene et al., 2009; Patrick \& Maggs, 2009) and extend earlier work by demonstrating that alcohol use is also associated with nonpenetrative sexual behaviors. Finally, the associations between alcohol use and sexual behaviors were stronger for college students when they were single, compared with when they were in casual or committed relationships, and (in some instances) when students reported greater expectancies that alcohol use leads to increases in sexual drive.

Students who were heavier drinkers on average across college reported kissing more often across their college years, but did not differ in their likelihood of other sexual behaviors. The lack of between-person associations between drinking and both oral and penetrative sex is in contrast to past cross-sectional and longitudinal studies demonstrating that people who drink more engage in more sexual behaviors than people who drink less (Cooper, 2002, 2006). However, our decomposition of effects into three levels-persons, semesters, and occasions-showed that alcohol use-sexual behavior links are primarily at the semester and occasion levels. The links between drinking and sex may have less to do with stable characteristics of individuals and more to do with a person's current 
TABLE 3

Multilevel Models Predicting Sexual Behaviors by Number of Drinks Using Daily Data

\begin{tabular}{|c|c|c|c|c|}
\hline & $\begin{array}{l}\text { Kissing } \\
\text { OR [CI] }\end{array}$ & $\begin{array}{l}\text { Touching } \\
\text { OR [CI] }\end{array}$ & $\begin{array}{c}\text { Oral } \\
\text { OR [CI] }\end{array}$ & $\begin{array}{c}\text { Penetrative } \\
\text { OR }[C I]\end{array}$ \\
\hline \multicolumn{5}{|l|}{ Level 3: Person level } \\
\hline Intercept & $0.01[0.01,0.02]^{* * *}$ & $0.01[0.01,0.01] * * *$ & $0.00[0.00,0.00]^{* * *}$ & $0.00[0.00,0.00]^{* * *}$ \\
\hline Male gender & $0.47[0.37,0.61]^{* * *}$ & $0.57[4.46,0.71]^{* * *}$ & $0.72[0.55,0.93]^{*}$ & $0.58[0.44,0.76]^{* * *}$ \\
\hline Age (at Semester 1) & $0.96[0.73,1.28]$ & $0.79[0.62,1.02]+$ & $0.76[0.57,1.02]+$ & $0.87[0.65,1.15]$ \\
\hline Person mean number drinks & $1.20[1.02,1.40]^{*}$ & $1.09[0.95,1.25]$ & $1.02[0.85,1.23]$ & $1.01[0.85,1.21]$ \\
\hline \multicolumn{5}{|l|}{ Level 2: Semester level } \\
\hline Semester (linear) & $1.03[0.99,1.08]$ & $0.99[0.95,1.03]$ & $1.05[1.00,1.10]^{*}$ & $1.07[1.02,1.12]^{* *}$ \\
\hline In a casual Relationship & $9.21[7.09,12.00] * * *$ & $5.79[4.57,7.33]^{* * *}$ & $4.33[3.19,5.87]^{* * *}$ & $5.26[3.96,7.01] * * *$ \\
\hline In a committed relationship & $18.54[14.63,23.48]^{* * *}$ & $10.33[8.40,12.71]^{* * *}$ & $10.13[7.92,12.96]^{* * *}$ & $13.62[10.73,17.28]^{* *}$ \\
\hline Alcohol-sex expectancies & $1.13[1.03,1.24]^{* *}$ & $1.30[1.20,1.41]^{* * *}$ & $1.41[1.28,1.55]^{* * *}$ & $1.39[1.26,1.54]^{* * *}$ \\
\hline Semester mean number drinks & $1.22[1.12,1.33]^{* * *}$ & $1.26[1.16,1.37]^{* * *}$ & $1.22[1.09,1.37]^{* *}$ & $1.25[1.11,1.40]^{* * *}$ \\
\hline \multicolumn{5}{|l|}{ Level 1: Daily level } \\
\hline Weekend & $1.50[1.38,1.63]^{* * *}$ & $1.73[1.57,1.91]^{* * *}$ & $1.93[1.70,2.19]^{* * *}$ & $1.71[1.52,1.92]^{* * *}$ \\
\hline Number of drinks & $1.29[1.23,1.35]^{* * *}$ & $1.21[1.16,1.27]^{* * *}$ & $1.21[1.14,1.28]^{* * *}$ & $1.17[1.11,1.24]^{* * *}$ \\
\hline$\times$ In a casual relationship & $0.92[0.87,0.97]^{* *}$ & $0.94[0.89,0.99]^{*}$ & $0.93[0.87,1.00]^{*}$ & $0.94[0.88,1.00]^{*}$ \\
\hline$\times$ In a committed relationship & $0.80[0.77,0.83]^{* * *}$ & $0.86[0.82,0.89]^{* * *}$ & $0.86[0.82,0.91] * * *$ & $0.87[0.83,0.92]^{* * *}$ \\
\hline$\times$ Alcohol-sex expectancies & $0.99[0.98,1.01]$ & $1.00[0.98,1.02]$ & $1.02[0.99,1.04]$ & $1.01[0.99,1.04]$ \\
\hline$\times$ Semester & $0.99[0.99,1.00]$ & $1.00[0.99,1.01]$ & $0.99[0.98,1.01]$ & $1.00[0.99,1.01]$ \\
\hline
\end{tabular}

Note. $\mathrm{OR}=$ odds ratio; $\mathrm{CI}=95 \%$ confidence interval; $\times$ = interactions of Level 1 Number of Drinks by Level 2 variables. Level $3 N=731$ persons, Level $2 N=4,345-4,347$ person-semesters, Level $1 N=55,318-55,372$ person-days. $+p<.10 ; * p<.05 ; * * p<.01 ; * * *<<.001$.

relationship status, expectancies about alcohol and sex, and the characteristics of the situation including day of the week and a person's level of alcohol use on a given day.

Previous studies that have attributed alcohol-sex links to enduring between-person differences have been unable to differentiate between these sources of variation. Additional three-level studies that can deconstruct person, developmental, and situational effects are needed to replicate results and test theory-based hypotheses about underlying mechanisms. Conclusions about etiology and implications for prevention could differ significantly depending on whether it is primarily specific to people, developmental or relational contexts (e.g., being single), or situations (e.g., intoxicated states) that increase the likelihood of sexual behaviors. The current findings suggest that prevention efforts should focus more on attitudes, relational contexts, and event-specific factors, rather than on types of people who engage in sexual behaviors. Given observed links between drinking and sexual behaviors at the daily level, prevention programs addressing alcohol use should also consider the effects of alcohol use on sexual behaviors, and efforts to reduce sexual risk should address alcohol use.

These findings are consistent with alcohol myopia (Steele \& Josephs, 1990) and expectancy theories (Lang, 1985). In particular, the stronger alcohol-sex links among students who were single (compared to those in casual or committed romantic relationships) are consistent with alcohol myopia theory. The effects of alcohol myopia-or intoxication leading to greater impact of the most salient cues, such as an available partner-may be more relevant and stronger for individuals without a romantic partner, whereas individuals who have established partners may engage in sexual behaviors regardless of whether they are drinking. On the other hand, the causal effects may be more complex. That is, alcohol may be especially likely to serve as an intentional social lubricant (Monahan \& Lannutti, 2000) for single people who specifically frequent venues where alcohol is served to meet potential sexual partners.

Consistent with alcohol expectancy theory (Coleman \& Cater, 2005; Cooper, 2006; Dermen et al., 1998), there was a trend for those who expected alcohol to increase their sexual drive to engage in oral or penetrative sex on days they also reported binge drinking. This daily link is independent of the tendency for sexual behaviors to be more likely during semesters when alcohol-sex expectancies were higher. It is possible that kissing and touching behaviors, although predicted by alcohol use, are less dependent on personal perceptions of alcohol's influence on sexual drive. It is important to 
TABLE 4

Multilevel Models Predicting Sexual Behaviors by Binge Drinking Using Daily Data

\begin{tabular}{|c|c|c|c|c|}
\hline & $\begin{array}{l}\text { Kissing } \\
O R[C I]\end{array}$ & $\begin{array}{l}\text { Touching } \\
\text { OR }[C I]\end{array}$ & $\begin{array}{c}\text { Oral } \\
\text { OR }[C I]\end{array}$ & $\begin{array}{c}\text { Penetrative } \\
\text { OR }[\mathrm{CI}]\end{array}$ \\
\hline \multicolumn{5}{|l|}{ Level 3: Person level } \\
\hline Intercept & $0.01[.01, .02] * * *$ & $0.01[0.01, .01] * * *$ & $0.00[0.00,0.00] * * *$ & $0.00[0.00,0.00] * * *$ \\
\hline Male gender & $0.56[0.44,0.71] * * *$ & $0.66[0.53,0.81]^{* * *}$ & $0.81[0.62,1.05]$ & $0.66[0.50,0.85]^{* *}$ \\
\hline Age (at Semester 1) & $0.95[0.72,1.26]$ & $0.77[0.61,0.99]^{*}$ & $0.75[0.56,1.00]^{*}$ & $0.85[0.64,1.13]$ \\
\hline Person mean binge drinking & $5.98[1.58,22.68]^{* *}$ & $3.19[0.98,10.35]+$ & $1.68[0.34,8.37]$ & $1.89[0.41,8.64]$ \\
\hline \multicolumn{5}{|l|}{ Level 2: Semester level } \\
\hline Semester (linear) & $1.03[0.99,1.08]$ & $0.99[0.96,1.03]$ & $1.05[1.00,1.10]^{*}$ & $1.07[1.02,1.12]^{* *}$ \\
\hline In a casual relationship & $9.66[7.45,12.54] * * *$ & $6.14[4.85,7.76] * * *$ & $4.56[3.37,6.17]^{* * *}$ & $5.39[4.06,7.16]^{* * *}$ \\
\hline In a committed relationship & $19.70[15.55,24.96]^{* * *}$ & $10.98[8.92,13.51] * * *$ & $10.65[8.32,13.64]^{* * *}$ & $13.92[10.97,17.66]^{* * *}$ \\
\hline Alcohol-sex expectancies & $1.13[1.03,1.23]^{*}$ & $1.29[1.19,1.40]^{* * *}$ & $1.40[1.28,1.55]^{* * *}$ & $1.39[1.26,1.54] * * *$ \\
\hline Semester mean binge drinking & $11.62[5.42,24.92] * * *$ & $11.26[5.42,23.36] * * *$ & $8.17[3.00,22.30] * * *$ & $8.60[3.27,22.60]^{* * *}$ \\
\hline \multicolumn{5}{|l|}{ Level 1: Daily level } \\
\hline Weekend & $1.45[1.33,1.58]^{* * *}$ & $1.68[1.53,1.86]^{* * *}$ & $1.88[1.65,2.14]^{* * *}$ & $1.69[1.51,1.90]^{* * *}$ \\
\hline Binge drinking & $10.53[7.88,14.05] * * *$ & $7.20[5.21,9.97]^{* * *}$ & $6.21[3.85,10.02] * * *$ & $4.38[2.78,6.90]^{* * *}$ \\
\hline$\times$ In a casual relationship & $0.32[0.22,0.47] * * *$ & $0.38[0.26,0.57]^{* * *}$ & $0.38[0.22,0.65]^{* *}$ & $0.42[0.25,0.70]^{* *}$ \\
\hline$\times$ In a committed relationship & $0.13[0.09,0.18] * * *$ & $0.20[0.15,0.29] * * *$ & $0.23[0.14,0.36]^{* * *}$ & $0.26[0.16,0.40] * * *$ \\
\hline$\times$ Alcohol-sex expectancies & $1.04[0.91,1.19]$ & $1.10[0.96,1.27]$ & $1.20[0.98,1.46]+$ & $1.18[0.98,1.42]+$ \\
\hline$\times$ Semester & $0.97[0.91,1.03]$ & $0.98[0.92,1.04]$ & $0.98[0.90,1.08]$ & $1.05[0.97,1.14]$ \\
\hline
\end{tabular}

Note. $\mathrm{OR}=$ odds ratio; $\mathrm{CI}=95 \%$ confidence interval; $\times=$ interactions of Level 1 binge drinking by Level 2 variables. Level $3 N=731$ persons, Level $2 N=4,345-4,347$ person-semesters, Level $1 N=55,318-55,372$ person-days. $+p<.10 ; * p<.05 ; * * p<.01 ; * * * p<.001$.

note that because the measure of alcohol-sex expectancies specifically uses the term "sex," participants may not have considered kissing and touching when answering these questions. More generally, our findings suggest that situational factors such as alcohol use affect sexual behaviors and that characteristics including relationship status and expectancies impact the extent to which alcohol use and sexual behaviors are linked.

The association between alcohol use and sexual behaviors did not change across the college years. Past work suggests that these links decrease with age starting in the early- to mid-20s (Dogan et al., 2010; Patrick et al., 2012). It is possible that we did not see change during this period because the social role of being a full-time student in a college environment is sufficiently homogeneous and stable. Notably, in any given semester, the majority of students were not in a romantic relationship. It may be that after the college years, when individuals are more likely to establish long-term, committed relationships and commence adult roles including those of full-time worker and parent, these associations may decrease (as does alcohol use more generally, e.g., Bachman et al., 2002). In a similar fashion, stronger alcohol-sex links may be maintained among those who remain single or may re-emerge among those who later separate or divorce.

\section{LIMITATIONS AND FUTURE DIRECTIONS}

There are also notable limitations. Data were from college students at a single university; thus, results may not generalize to other settings. In particular, young adults who do not attend college tend to have earlier engagement in marriage and full-time employment (Bachman et al., 2002), which might attenuate these associations earlier. Relationship status was reported immediately prior to the 14-day diary period each semester. Thus, any changes in relationship status during the daily diary period could not be modeled.

Future research should seek to replicate and extend these findings with adolescent, college student (including community college, commuter, and urban campuses), and nonstudent young adult populations. A focus on additional moderators, such as age, sensation-seeking, conscientiousness, religiosity, and previous sexual experience, could help identify persons for whom alcohol use and sexual behaviors are more tightly linked. Furthermore, understanding adolescents' and young adults' perceived positive and negative consequences of a range of sexual behaviors on days when they do versus do not use alcohol would help to illuminate the subjective experience of co-occurring alcohol use and sexual behaviors in this developmental period and provide important 
information about the meaning of nonpenetrative sexual behaviors for young adults (Tolman \& McClelland, 2011; Welsh et al., 2005). In addition, future work should consider examining adolescents' and young adults' own perceptions of how their alcohol use and sexual behaviors are linked to understand which associations between alcohol use and sex are most salient to young people. Understanding how individuals experience the day-today co-occurrence of behaviors such as alcohol use and sexual behaviors and whether this association emerges and perhaps wanes across adolescence and young adulthood will provide a broader basis for developmental theories and intervention programs that integrate multiple behaviors.

\section{REFERENCES}

Abbey, A., McAuslan, P., Ross, L. T., \& Zawacki, T. (1999). Alcohol expectancies regarding sex, aggression, and sexual vulnerability: Reliability and validity assessment. Psychology of Addictive Behaviors, 13, 174182. doi:10.1037/0893-164X.13.3.174

American College Health Association. (2007). National college health assessment: Reference group executive summary Spring 2008. Baltimore, MD: American College Health Association. Retrieved January 9, 2014, from http:// www.acha-ncha.org/reports_ACHA-NCHAoriginal.html

Bachman, J. G., O'Malley, P. M., Schulenberg, J. E., Johnston, L. D., Bryant, A. L., \& Merline, A. C. (2002). The decline of substance use in young adulthood: Changes in social activities, roles, and beliefs. Mahwah, NJ: Lawrence Erlbaum.

Bailey, S. L., Gao, W., \& Clark, D. B. (2006). Diary study of substance use and unsafe sex among adolescents with substance use disorders. Journal of Adolescent Health, 38, 297.e213-297.e220. doi:10.1016/j.jadohealth. 2004.12.001

Barta, W. D., Portnoy, D. B., Kiene, S. M., Tennen, H., Abu-Hasaballah, K. S., \& Ferrer, R. (2008). A daily process investigation of alcohol-involved sexual risk behavior among economically disadvantaged problem drinkers living with HIV/AIDS. AIDS and Behavior, 12, 729-740. doi:10.1007/s10461-007-9342-4

Brown, S. A., McGue, M., Maggs, J. L., Schulenberg, J. E., Hingson, R., Swartzwelder, S., ... Murphy, S. (2008). A developmental perspective on alcohol and youths 16 to 20 years of age. Pediatrics, 121(Suppl. 4), S290-S310. doi:10.1542/peds.2007-2243D

Brown, J. L., \& Vanable, P. A. (2007). Alcohol use, partner type, and risky sexual behavior among college students: Findings from an event-level study. Addictive Behaviors, 32, 2940-2952. doi:10.1016/j.addbeh.2007.06.011

Coleman, L. M., \& Cater, S. M. (2005). A qualitative study of the relationship between alcohol consumption and risky sex in adolescents. Archives of Sexual Behavior, 34, 649-661. doi:10.1007/s10508-005-7917-6
Cooper, M. L. (2002). Alcohol use and risky sexual behavior among college students and youth: Evaluating the evidence. Journal of Studies on Alcohol, 14 (Suppl.), 101-117.

Cooper, M. L. (2006). Does drinking promote risky sexual behavior?: A complex answer to a simple question. Current Directions in Psychological Science, 15, 19-23. doi:10.1111/j.0963-7214.2006.00385.x

Dermen, K. H., \& Cooper, M. L. (2000). Inhibition conflict and alcohol expectancy as moderators of alcohol's relationship to condom use. Experimental and Clinical Psychopharmacology, 8, 198-206. doi:10.1037/1064-1297.8.2.198

Dermen, K. H., Cooper, M. L., \& Agocha, V. B. (1998). Sex-related alcohol expectancies as moderators of the relationship between alcohol use and risky sex in adolescents. Journal of Studies on Alcohol, 59, 71-77.

Diamond, L. M., \& Savin-Williams, R. C. (2009). Adolescent sexuality. In R. M. Lerner \& L. Steinberg (Eds.), Handbook of adolescent psychology: Individual bases of adolescent development (3rd ed., pp. 479-523). Hoboken, NJ: John Wiley.

Dogan, S. J., Stockdale, G. D., Widaman, K. F., \& Conger, R. D. (2010). Developmental relations and patterns of change between alcohol use and number of sexual partners form adolescence through adulthood. Developmental Psychology, 46, 1747-1759. doi:10.1037/a0019655

Fromme, K., Corbin, W. R., \& Kruse, M. I. (2008). Behavioral risks during the transition from high school to college. Developmental Psychology, 44, 1497-1504. doi:10. $1037 / \mathrm{a} 0012614$

Gillmore, M. R., Morrison, D. M., Leigh, B. C., Hopee, M. J., Gaylord, J., \& Rainey, D. T. (2002). Does "high = high risk"? An event-based analysis of the relationship between substance use and unprotected anal sex among gay and bisexual men. AIDS and Behavior, 6, 361-369. doi:10.1023/ A:1021104930612

Griffin, J. A., Umstattd, R., \& Usdan, S. L. (2010). Alcohol use and high-risk sexual behavior among collegiate women: A review of research on alcohol myopia theory. Journal of American College Health, 58, 523-532. doi:10.1080/07448481003621718

Hingson, R., Heeren, T., Winter, M., \& Wechsler, H. (2005). Magnitude of alcohol-related mortality and morbidity among U.S. college students ages 18-24: Changes from 1998 to 2001. Annual Review of Public Health, 26, 259-279. doi:10.1146/annurev.publhealth.26. 021304.144652

Hingson, R. W., Heeren, T., Zakocs, R. C., Kopstein, A., \& Wechsler, H. (2002). Magnitude of alcohol-related mortality and morbidity among U.S. college students ages 18-24. Journal of Studies on Alcohol, 63, 136-144.

Johnston, L. D., O'Malley, P. M., Bachman, J. G., \& Schulenberg, J. E. (2013a). Monitoring the Future national survey results on drug use, 1975-2012. Volume II: College students and adults ages 19-50. Ann Arbor: Institute for Social Research, The University of Michigan.

Johnston, L. D., O'Malley, P. M., Bachman, J. G., Schulenberg, J. E., Patrick, M. E., \& Miech, R. A. (2013b). HIV/ 
AIDS: Risk and protective behaviors among American young adults, 2004-2012. Ann Arbor: Institute for Social Research, The University of Michigan.

Kaly, P. W., Heesacker, M., \& Frost, H. M. (2002). Collegiate alcohol use and high-risk sexual behavior: A literature review. Journal of College Student Development, 43, 838-850. doi:10.1080/07448481003621718

Kiene, S. M., Barta, W. D., Tennen, H., \& Armeli, S. (2009). Alcohol, helping young adults to have unprotected sex with casual partners: Findings from a daily diary study of alcohol use and sexual behavior. Journal of Adolescent Health, 44, 73-80. doi:10.1016/j.jadohealth. 2008.05.008

LaBrie, J., Earleywine, M., Schiffman, J., Pedersen, E., \& Marriot, C. (2005). Effects of alcohol, expectancies, and partner type on condom use in college males: Eventlevel analyses. Journal of Sex Research, 42, 259-266. doi:10.1080/00224490509552280

Lang, A. R. (1985). The social psychology of drinking and human sexuality. Journal of Drug Issues, 15, 273-289.

Lefkowitz, E. S., \& Gillen, M. M. (2005). "Sex is just a normal part of life": Sexuality in emerging adulthood. In J. J. Arnett \& J. L. Tanner (Eds.), Emerging adults in America: Coming of age in the 21st century (pp. 235-255). Washington, DC: American Psychological Association.

Leigh, B. C. (1993). Alcohol consumption and sexual activity as reported with a diary technique. Journal of Abnormal Psychology, 102, 490-493. doi:10.1037/0021843X.102.3.490

Leigh, B. C., Ames, S. L., \& Stacy, A. W. (2008). Alcohol, drugs, and condom use among drug offenders: An event-based analysis. Drug and Alcohol Dependence, 93, 38-42. doi:10.1016/j.drugalcdep.2007.08.012

MacDonald, T. K., Fong, G. T., Zanna, M. P., \& Martineau, A. M. (2000). Alcohol myopia and condom use: Can alcohol intoxication be associated with more prudent behavior? Journal of Personality and Social Psychology, 78, 605-619. doi:10.1037/0022-3514.78.4.605

Maggs, J. L., Williams, L. R., \& Lee, C. M. (2011). Ups and downs of alcohol use among first-year college students: Drinks per day, heavy drinking, and stumble and pass out drinking. Addictive Behaviors, 36, 197-202. doi:10.1016/j.addbeh.2010.10.005

Monahan, J. L., \& Lannutti, P. J. (2000). Alcohol as social lubricant: Alcohol myopia theory, social self-esteem, and social interaction. Human Communication Research, 26, 175-202. doi:10.1111/j.1468-2958.2000.tb00755.x

Mustanski, B. (2008). Moderating effects of age on the alcohol and sexual risk taking association: An online daily diary study of men who have sex with men. AIDS and Behavior, 12, 118-126. doi:10.1007/s10461007-9335-3

Neal, D. J., \& Fromme, K. (2007). Event-level covariation of alcohol intoxication and behavioral risks during the first year of college. Journal of Consulting and Clinical Psychology, 75, 294-306. doi:10.1037/0022-006X.75.2.294

Nesselroade, J. R. (1991). The warp and woof of the developmental fabric. In R. Downs, L. Liben, \& D.
Palermo (Eds.), Visions of development, the environment, and aesthetics: The legacy of Joachim F. Wohlwill (pp. 213240). Hillsdale, NJ: Lawrence Erlbaum.

Patrick, M. E., \& Maggs, J. L. (2009). Does drinking lead to sex? Daily alcohol-sex behaviors and expectancies among college students. Psychology of Addictive Behaviors, 23, 472-481. doi:10.1037/a0016097

Patrick, M. E., Maggs, J. L., \& Osgood, D. W. (2010). LateNight Penn State alcohol-free programming: Students drink less on days they participate. Prevention Science, 11, 155-162. doi:10.1007/s11121-009-0160-y

Patrick, M. E., O’Malley, P. M., Johnston, L., Terry-McElrath, Y. M., \& Schulenberg, J. E. (2012). HIV / AIDS risk behaviors and substance use by young adults in the United States. Prevention Science, 13, 532-538. doi:10. 1007/s11121-012-0279-0

Pedersen, E. R., Lee, C. M., Larimer, M. E., \& Neighbors, C. (2009). Gender and dating relationship status moderate the association between alcohol use and sexrelated alcohol expectancies. Addictive Behaviors, 34, 786-789. doi:10.1016/j.addbeh.2009.04.015

Perkins, H. W. (2002). Surveying the damage: A review of research on consequences of alcohol misuse in college populations. Journal of Studies on Alcohol, 14 (Suppl.), 91-100.

Raudenbush, S. W., \& Bryk, A. S. (2002). Hierarchical linear models: Applications and data analysis methods (2nd ed.) Thousand Oaks, CA: Sage.

Sliwinski, M. J. (2008). Measurement-burst designs for social health research. Social and Personality Psychology Compass, 2, 245-261. doi:10.1111/j.1751-9004.2007. 00043.x

Steele, C. M., \& Josephs, R. A. (1990). Alcohol myopia: Its prized and dangerous effects. American Psychologist, 45, 921-933. doi:10.1037/0003-066X.45.8.921

Tolman, D. L., \& McClelland, S. I. (2011). Normative sexuality development in adolescence: A decade in review, 2000-2009. Journal of Research on Adolescence, 21, 242-255. doi:10.1111/j.1532-7795.2010.00726.x

Vasilenko, S. A., Lefkowitz, E. S., \& Maggs, J. L. (2012). Short-term positive and negative consequences of sex based on daily reports among college students. Journal of Sex Research, 49, 558-569. doi:10.1080/00224499.2011. 589101

Wechsler, H., \& Nelson, T. (2001). Binge drinking and the American college student: What's five drinks? Psychology of Addictive Behaviors, 15, 287-291. doi:10.1037/ 0893-164X.15.4.287

Welsh, D. P., Haugen, P. T., Widman, L., Darling, N., \& Grello, C. M. (2005). Kissing is good: A developmental investigation of sexuality in adolescent couples. Sexuality Research and Social Policy, 2, 32-41. doi:10.1525/srsp. 2005.2.4.32

White, H. R., Fleming, C. B., Catalano, R. F., \& Bailey, J. A. (2009). Prospective associations among alcohol userelated sexual enhancement expectancies, sex after alcohol use, and casual sex. Psychology of Addictive Behaviors, 23, 702-707. doi:10.1037/a0016630 